\title{
Yabani Korunga Türlerinden Onobrychis oxyodonta ve Onobrychis gracilis Meyvelerinin Çimlenme Yüzdelerinin Artırılması
}

\author{
Altıngül Özaslan Parlak* Sedat Çankaya Fatih Yıldız \\ ÇOMÜ Ziraat Fakültesi, Tarla Bitkileri Bölümü. 17100/Çanakkale \\ *Sorumlu yazar: ozaslan@comu.edu.tr
}

Geliş Tarihi: 11.02.2019

Kabul Tarihi: 27.06.2019

$\ddot{O} \mathbf{z}$

Çok yıllık yabani korungalar mera 1slahında kullanılabilecek en önemli bitkilerdir. Fakat yabani baklagillerde dormansi yüksek oranlarda bulunmaktadır. Bu bitkilerde dormansi kırılarak ve bitkilerin tarımsal değerleri ortaya konarak tarıma kazandırılmalıdır. Bu çalışmada yabani korunga türlerinden Onobrychis oxyodonta ve Onobrychis gracilis meyvelerine bazı ön uygulamalar yapılarak ve çimlenme yüzdelerinin artırılması amaçlanmıştır. Bu çok yıllık yabani korunga türlerinin (Onobrychis oxyodonta ve Onobrychis gracilis) meyvelerine fiziksel ve kimyasal ön uygulamalar yapılmıştır. Fiziksel uygulamalarda meyveler $70^{\circ} \mathrm{C}$ ve $80^{\circ} \mathrm{C}$ 'deki saf suda 5,10 ve 15 dakika bekletme, $100^{\circ} \mathrm{C}$ 'deki saf suya daldırma ve zımparalama uygulamaları yapılmıştır. Kimyasal uygulamalarda ise meyveler \%96'llk ve \%70'lik sülfürik asit $\left(\mathrm{H}_{2} \mathrm{SO}_{4}\right)$ çözeltisinde 1, 2 ve 5 dakika bekletilmiştir. Onobrychis gracilis meyvelerinde \%96'llk sülfürik asit uygulamasında hiç çimlenme gözlenmemiştir. Her iki tür içinde kimyasal uygulamalardan istatistiki olarak önemli bir sonuç alınamamıştır. Onobrychis oxyodonta meyveleri $100^{\circ} \mathrm{C}^{\prime}$ deki suya daldırma ile $70^{\circ} \mathrm{C}$ 'de $5,10,15 \mathrm{dk}$. bekletme ve zımparalama uygulamalarında en yüksek oranda çimlenme tespit edilmiştir. Onobrychis gracilis meyvelerinde de çimlenme oranında $\% 51,00$ ile en büyük artış $100^{\circ} \mathrm{C}$ 'deki suya daldırma uygulamasında görülmüştür. Bu uygulamayı $70^{\circ} \mathrm{C}$ 'de 5,10 ve $15 \mathrm{dk}$. ile $80{ }^{\circ} \mathrm{C}$ 'de $5 \mathrm{dk}$ bekletme uygulamaları takip etmiştir. Bu sonuçlara göre çok yıllık yabani korungaların çimlenme yüzdesini artırmak için sıcak su veya zımparalama uygulamasının yapılması tavsiye edilmelidir.

Anahtar Kelimeler: Onobrychis oxyodonta, Onobrychis gracilis, çimlenme oranı, dormansi

\section{Enhancing the Germination Percentage Ratios of the Fruits of Onobrychis oxyodonta and Onobrychis gracilis from Wild Sainfoin Species}

\section{Abstract}

Perennial wild sainfoin species are the most important plants that can be used for rangelands improvement. But its dormancy is found in high rates among wild legumes. These plants should be cultivated by breaking their dormancy first and then revealing the agricultural values of the plants. It has been aimed in this study to increase the germination percentage ratios by applying some pre-treatments to Onobrychis oxyodonta and Onobrychis gracilis fruits from wild sainfoin species. Pre-treatments, physical and chemical applications, have been applied to the fruits of these perennial wild sainfoin species (Onobrychis oxyodonta and Onobrychis gracilis). The fruits were kept in distilled water at the temperature levels of $70^{\circ} \mathrm{C}$ and $80^{\circ} \mathrm{C}$ for 5,10 and 15 minutes in physical applications, and the dipping and grinding applications have been done in distilled water at $100^{\circ} \mathrm{C}$. The fruits have been kept for 1,2 and 5 minutes in $96 \%$ and $70 \%$ of sulfuric acid $\left(\mathrm{H}_{2} \mathrm{SO}_{4}\right)$ solution in case of chemical applications, but no germination was observed in the application of $96 \%$ sulfuric acid in fruits of Onobrychis gracilis. The obtained results from chemical applications were statistically non-significant in case of both species. Fruits of Onobrychis oxyodonta, kept in distilled water at $100^{\circ} \mathrm{C}$ for $5,10,15$ minutes by dipping application, were found to be the highest in germination at $70^{\circ} \mathrm{C}$ in case of grinding application. The highest increase, in fruit germination rates of Onobrychis gracilis with $51.00 \%$, was observed in the distilled water at $100^{\circ} \mathrm{C}$ in dipping application. This application has been followed by the applications of $70^{\circ} \mathrm{C}$ kept in distilled water for 5,10 and 15 minutes, and $80^{\circ} \mathrm{C}$ kept for 5 minutes. According to these results, it is suggested to apply hot water treatment or grinding application for increasing the germination percentage ratio of perennial wild sainfoin species.

Keywords: Onobrychis oxyodonta, Onobrychis gracilis, germination ratios, dormancy

\section{Giriş}

Korunga bitkisi baklagil olması, hayvanlarda şişme yapmaması, kurak alanlarda yetişebilen bir bitki olmasından dolayı oldukça önemlidir. Korunda bitkisi köklerindeki nodozite bakterileri sayesinde havanın serbest azotunu toprağa bağladığından dolayı toprağın verimliliğini artırdığı gibi, 
otunda ham protein oranının yüksek olmasından dolayı hayvanlar için kaliteli kaba yem üretmektedir. Korunganın yabani türlerinden olan Onobrychis oxyodonta, Onobrychis gracilis bitkileri çok yıllıktır. Çok yıllık oldukları için yapay mera ve mera 1slah çalışmalarında kullanılabilecek önemli bitkilerdir. Özellikle mera 1slah çalışmalarında bölgeye adapte olmuş yem bitkilerinin kullanılması başarı şansını artıracaktır. Doğal meralarda ot kalitesi ve verimi yüksek olan bitkilerin tarıma kazandırılması meraların iyileştirilmesinde başarıya ulaşmanın temel ilkelerinden biridir. Özaslan-Parlak ve ark., (2014) O. caput-galli, O. oxyodonta,O. gracilis türlerinin morfolojik ve agronomik özelliklerini belirlemişlerdir. $\mathrm{Bu}$ türlerden çok yıllık olan $O$. oxyodonta, O. gracilis mera 1slahlarında kullanılabilecek bitki olarak tespit etmişler özellikle $O$. oxyodonta'nın meyvelerinin dikensiz olmasından dolayı öneminin daha fazla olduğunu belirtmişlerdir. Fakat bu bitkiler yabani oldukları için dormansi oldukça yüksektir. Bazı ön uygulamalarla çimlenme yüzdesi artırılabilir. Korunganın iki yabani türünün meyvelerine (O. melanotricha, $O$. sintenisii) soğuk uygulaması, fiziksel ve kimyasal uygulamalar yapılmıştır. Meyvelerin çimlenmesi üzerine soğuk uygulamalarının hiçbir etkisi olmazken, kimyasal uygulama çimlenmeyi düşürmüş, fiziksel uygulama ise çimlenmeyi artırmışıır (Majidi ve Barati 2011). Bu çalışmada korunganın iki yabani türü olan O. oxyodonta,O. gracilis'in meyvelerine fiziksel ve kimyasal aşındırma uygulayarak çimlenme yüzdelerinin artırılması hedeflenmiştir.

\section{Materyal ve Yöntem}

İki yabani korunga türleri ( $O$. oxyodonta, $O$. gracilis) Çanakkale Onsekiz Mart Üniversitesi Terzioğlu Yerleşkesinden temmuz ayında toplanmıştır. Özaslan-Parlak ve ark., (2014) bu iki korunga türü ile yaptıkları çalışmada; $O$. oxyodonta'nın meyveleri kültür korungasından küçük ve dikensiz olduğunu bitkinin dik geliştiğini, ortalama bitki boyunun $60,71 \mathrm{~cm}$, kuru madde veriminin $6,27 \mathrm{~g} / \mathrm{bitki}$, bin dane ağırlı̆̆ının 11,34 g olarak belirlerken, O. gracilis de ise meyvelerin dikenli olup bitki yarı yatık geliştiğini, ortalama bitki boyunun $58,00 \mathrm{~cm}$ olduğunu, kuru madde veriminin $6,57 \mathrm{~g} / \mathrm{bitki}$, bin dane ağırlığının 9,53 g olduğunu belirlemişlerdir.

Korunga meyvelerinin çimlenme oranlarını yükseltebilmek için deneme Tarla Bitkileri Laboratuarında kurulmuştur. Meyvelerin petri kaplarında çimlendirmek için; meyveler 4 tekerrür olarak yüzer, yüzer sayılmışır. Petri kapları ve meyveler \%1'lik sodyum hipoklorit çözeltisinden geçirildikten sonra saf suya daldırılarak durulanmıştır. Çimlendirme kağıtları petri kaplarına göre kesilerek petri kaplarına yerleştirilmiştir.

Meyvelere çimlenmeyi artırmak için yapılan uygulamalar:

1. Kontrol: Meyvelere hiçbir işlem uygulamadan çimlendirmeye bırakılmıştır.

2. Meyvelere zımpara uygulaması: Meyvelere 2-3 dakika süresince iki zımpara kağıdı arasında zımparalama işlemi yapılmıştır.

3. Meyvelere sülfürik asit $\left(\mathrm{H}_{2} \mathrm{SO}_{4}\right)$ uygulaması: a. \%96'lık çözeltide 1, 2 ve 5 dk bekletmek, b. $\% 70$ çözeltide 1,2 ve $5 \mathrm{dk}$ bekletmek.

4. Meyvelerin farklı sıcaklıklardaki suda belirli süre bekletilmesi: a. $70{ }^{\circ} \mathrm{C}$ 'de 5,10 ve $15 \mathrm{dk}$ bekletmek, b. $80{ }^{\circ} \mathrm{C}$ 'de 5,10 ve $15 \mathrm{dk}$ bekletmek, c. $100{ }^{\circ} \mathrm{C}$ 'de daldırıp çıkarmak (PerezGarcia ve Gonzalez-Benito 2006).

Yapılan farklı uygulamalardan sonra petri kapları inkübatöre konularak 5 hafta $20{ }^{\circ} \mathrm{C}$ 'de karanlık ortamda bekletilmiştir. İlk sayım işlemi inkübatöre konulduktan 7 gün sonra yapılmıştır. Sonraki sayımlara 14., 21., 28., ve 35. günlerde devam edilmiştir. Okumalarda petri kaplarının nemi aynı olması için saf su eklenmiştir. Sayımlar 35. günde sona erdirilerek elde edilen veriler doğrultusunda uygulamalar sonucu oluşan çimlenme oranları tespit edilmiştir (Nadjafi ve ark.,2006).

Verilerin değerlendirilmesi: Hesaplanan çimlenme yüzdelerine arc-sinüs transformasyonu uygulandıktan sonra tek yönlü ANOVA ile varyans analizi yapılmıştır. Ortalamalar arasındaki farkın önemlilik derecesini belirlemek için Duncan çoklu karşılaştırma testi kullanılmıştır.

\section{Bulgular ve Tartışma}

Çok yıllık yabani korungaların meyvelerine uygulanan fiziksel ve kimyasal uygulamalar sonucunda çimlenme üzerine önemli etkileri olmuştur (Çizelge 1). O. oxyodonta' nın çimlenmesi sülfirik asit uygulamalarında önemli derecede azalmış, zımparalama ve sıcak su uygulamalarında ise 
önemli derecede artmıştır. En fazla çimlenme ise $70{ }^{\circ} \mathrm{C}$ sıcak su uygulamasında belirlenmiştir. $70{ }^{\circ} \mathrm{C}$ uygulamasına ait bütün bekletme sürelerinde aynı istatistiki grupta yer almıştır. Meyvelerin $70^{\circ} \mathrm{C}$ ' de 5,10 ve $15 \mathrm{dk}$. bekletmelerde sirasiyla çimlenme $\% 58,50, \% 59,75$ ve $\% 58,25$ olarak tespit edilmiştir. $\mathrm{Bu}$ uygulamaları $100{ }^{\circ} \mathrm{C}$ 'ye daldırıp çıkarma ve zımparalama uygulamaları takip etmiştir ve aynı istatistiki grupta yer almıştır.

O. gracilis meyvelerinde \%96'lık sülfirik asit uygulamasında meyveler tamamen canlılı̆̆ını yitirmiştir. \%70'lik $\mathrm{H}_{2} \mathrm{SO}_{4}$ uygulamalarında 1 dk'lık bekletme kontrolle aynı olurken, 2 ve $5 \mathrm{dk}$ 'llk bekletmelerde çimlenme oranının arttığı belirlenmiştir. O. oxyodonta da olduğu gibi $O$. gracilis'de de sıcak su uygulamaları çimlenmeyi artırmıştır. En fazla çimlenme $\% 51,00$ ile $100{ }^{\circ} \mathrm{C}$ suya daldırıp çıkarma uygulamasında olmuştur, bunu $70^{\circ} \mathrm{C}$ sıcak suda 5,10 ve $15 \mathrm{dk} ., 80{ }^{\circ} \mathrm{C}$ 'de $5 \mathrm{dk}$. bekletme takip ederek aynı istatistiki grupta yer almıştır. Bu uygulamaları sırasıyla $80{ }^{\circ} \mathrm{C}$ 'de 10 ve $15 \mathrm{dk}$. bekletme ile zımparalama uygulamaları takip etmiştir (Çizelge 1).

Çizelge 1. Çok yıllık yabani korunga Onobrychis oxyodonta, Onobrychis gracilis meyvelerine yapılan fiziksel ve kimyasal uygulamalar sonucu oluşan çimlenme oranları.

\begin{tabular}{|c|c|c|c|}
\hline \multirow{2}{*}{\multicolumn{2}{|c|}{ Yapılan Uygulamalar }} & \multicolumn{2}{|c|}{ Ortalama \pm Standar Sapma } \\
\hline & & Onobrychis oxyodonta & Onobrychis gracilis \\
\hline \multicolumn{2}{|l|}{ 1.Kontrol } & $33,00 \pm 7,257 \mathrm{~b}^{*}$ & $14,25 \pm 1,258 \mathrm{e}$ \\
\hline \multicolumn{2}{|c|}{ 2.Zımparalama } & $51,75 \pm 8,846 \mathrm{a}$ & $22,00 \pm 3,266 \mathrm{cde}$ \\
\hline \multicolumn{2}{|c|}{ 3. $\mathrm{H}_{2} \mathrm{SO}_{4} \% 961 \mathrm{dk}$} & $4,25 \pm 2,500$ ef & $0,00 \pm 0,000 \mathrm{f}$ \\
\hline 4. & $2 \mathbf{d k}$ & $12,75 \pm 2,986 \mathrm{cde}$ & $0,00 \pm 0,000 \mathrm{f}$ \\
\hline 5. & $5 \mathrm{dk}$ & $14,25 \pm 1,500 \mathrm{~cd}$ & $0,00 \pm 0,000 \mathrm{f}$ \\
\hline \multicolumn{2}{|c|}{ 6. $\mathrm{H}_{2} \mathrm{SO}_{4} \% 701 \mathrm{dk}$} & $7,25 \pm 4,193 \mathrm{def}$ & $14,25 \pm 3,304 \mathrm{e}$ \\
\hline 7. & $2 \mathbf{d k}$ & $1,00 \pm 0,000 \mathrm{f}$ & $17,50 \pm 4,435 \mathrm{de}$ \\
\hline 8. & $5 \mathrm{dk}$ & $6,00 \pm 0,816 \mathrm{def}$ & $25,50 \pm 7,000 \mathrm{~cd}$ \\
\hline $9.70^{\circ} \mathrm{C}$ & $5 \mathbf{d k}$ & $58,50 \pm 2,380 \mathrm{a}$ & $36,00 \pm 6,532 \mathrm{~b}$ \\
\hline 10. & $10 \mathrm{dk}$ & $59,75 \pm 7,274 \mathrm{a}$ & $43,00 \pm 7,024 b$ \\
\hline 11. & $15 \mathrm{dk}$ & $58,25 \pm 6,500 \mathrm{a}$ & $38,50 \pm 11,475 b$ \\
\hline $12.80^{\circ} \mathrm{C}$ & $5 \mathbf{d k}$ & $36,75 \pm 9,570 \mathrm{~b}$ & $39,00 \pm 3,830 \mathrm{~b}$ \\
\hline 13. & $10 \mathrm{dk}$ & $19,75 \pm 6,021 \mathrm{c}$ & $25,50 \pm 9,292 \mathrm{~cd}$ \\
\hline 14. & $15 \mathrm{dk}$ & $17,25 \pm 4,573 \mathrm{c}$ & $26,50 \pm 1,915 \mathrm{c}$ \\
\hline \multicolumn{2}{|c|}{ 15. $100^{\circ} \mathrm{C}$ daldırma } & $56,50 \pm 10,214 \mathrm{a}$ & $51,00 \pm 5,292 \mathrm{a}$ \\
\hline
\end{tabular}

*Küçük harfler $\% 5$ düzeyinde farklı grupları göstermektedir.

Özellikle $O$. oxyodonta meyvelerinin çimlenmesine zımparalama etkili olmuştur. Benzer sonuçları Hardegree ve Emmerich (1991) de bulmuştur. Ibanez ve Passera (1997) Anthyllis cytisoides L. bitkisinde, Perez-Garcia ve Gonzalez-Benito (2006) Helianthemum türleriyle, Uzun ve Aydın (2004) Medicago ve Trifolium türleriyle çimlendirmeyi artırmak için yaptıkları çalışmalarda en fazla çimlenme mekanik olarak yapılan aşındırmalarda olmuştur. Baskin ve Baskin (1998) baklagillerde tohum kabuğunu kırmak için yapılan mekanik uygulamaların doğada meydana gelen günlük sıcaklık değişimlerinin, yağmur ve kar sularının, kurak ve yaş peryotların, toprak partiküllerinin ve mikrobiyal aktivitelerin benzerliğinden bahsederek mekanik uygulamaların daha fazla çimlendirmeyi artırdığını bildirmektedir.

O. gracilis meyveleri \%96'llk süfirik asitte $\left(\mathrm{H}_{2} \mathrm{SO}_{4}\right) 1,2$, ve $5 \mathrm{dk}$ bekletme uygulamalarında çimlenme meydana gelmemiştir. Benzer durum Perez-Garcia ve Gonzalez-Benito (2006) tarafindan da Helianthemum almeriense türünde, Ibanez ve Passera (1997) Anthyllis cytisoides L. türünde, Gökkuş ve ark. (2009) Cistus creticus çalısı ile Medicago minima ve Trifolium striatum türlerinde belirlemişlerdir. Majidi ve barati (2011)'de Onobrychis melanotricha ile Onobrychis sintenisii türlerinde çimlenmeyi artırmak için yaptığ 1 çalışmada yaptığımız çalışmada olduğu gibi kimyasal uygulamaların çimlenmeyi düşürdüğünü, fiziksel uygulamaların çimlenmeyi artırdığını belirlemişlerdir. 


\section{Sonuç ve Öneriler}

Her iki tür içinde kimyasal uygulamalardan istatistiki olarak önemli bir sonuç alınamamıştır. Onobrychis oxyodonta meyveleri $100^{\circ} \mathrm{C}$ 'deki suya daldırma ile $70{ }^{\circ} \mathrm{C}$ 'de 5,10 ve 15 dk. bekletme ve zımparalama uygulamalarında en yüksek oranda çimlenme tespit edilmiştir. Onobrychis gracillis meyvelerinde de çimlenme oranında $\% 51,00$ ile en büyük artış $100{ }^{\circ} \mathrm{C}^{\prime}$ 'deki suya daldırma uygulamasında görülmüştür. Bu uygulamay $70{ }^{\circ} \mathrm{C}$ 'de 5,10 ve $15 \mathrm{dk}$ ile $80{ }^{\circ} \mathrm{C}$ 'de $5 \mathrm{dk}$ bekletme uygulamaları takip etmiştir. $\mathrm{Bu}$ sonuçlara göre çok yıllık yabani korunga meyvelerinin çimlenme yüzdesini artırmak için sıcak su veya zımparalama uygulamasının yapılması tavsiye edilebilir.

Not: Makale II.Çanakkale Tarımı Sempozyumunda özet bildiri olarak basılmıştır.

\section{Kaynaklar}

Baskin, C.C., Baskin, J.M., 1998. Seeds: Ecology, Biogeography, and Evolution of Dormancy and Germination. Academic Press, San Diego 666pp.

Gökkuş, A., Özaslan-Parlak, A., Poyraz, N., Çalışkan, Ö., Balıca, M., 2009. Akdeniz iklim kuşağının çalılı meralarında otlanan bazı çalı ve yıllık baklagillerin tohumla çoğaltılması. VIII. Tarla Bitkileri Kongresi, 19-22 Ekim, Hatay: 539-542.

Hardegree, S.P.,Emmerich, W.E., 1991. Variability in germination rate among seed lots of Lehmann lovegrass. Journal of Range Management, 44: 323-326.

Ibanez, A.N., Passera, C.B., 1997. Factors affecting the germination of albaida (Anthyllis cytisoides L.), a forage legume of the Mediterranean coast. Journal of Arid Environments. 35: 225-231.

Majidi, M.M., Barati, M., 2011. Methods for breaking seed dormancy in one cultivated and two wild Onobrychis species. Seed Science and Technology. 9(1): 44-53.

Nadjafi, F., Bannayan, M., Tabrizi, L., Rastgoo, M., 2006. Seed germination and dormancy breaking techniques for Ferula gummosa and Teucrium polium. Journal of Arid Environments. 64:542-547.

Özaslan-Parlak, A., Gökkuş, A., Samıkıran, E., Şenol, M.Y., 2014. Bazı yabani korunga türlerinin morfolojik ve agronomik özelliklerinin incelenmesi. ÇOMÜ Ziraat Fakültesi Dergisi. 2(2): 111-117.

Perez-Garcia, F., Gonzalez-Benito, M.E., 2006. Seed germination of five Helianthemum species: Effect of temperature and presowing treatments. Journal of Arid Environments. 65: 688-693.

Uzun, F., Aydın, İ., 2004. Improving germination rate of Medicago and Trifolium species. Asian Journal of Plant Sciences. 3(6): 714-717. 